\title{
Integrating Communication Skills into Undergraduate Science Degrees: A Practical and Evidence-Based Approach
}

\author{
ABSTRACT \\ The introduction of generic skills, such as communication, into undergraduate science \\ degrees is becoming common in higher education and has met with mixed \\ implementation success. This study designed, piloted, and evaluated a set of adaptable \\ activities that scaffold the explicit teaching and learning of science communication with \\ non-scientific audiences. These activities were implemented in undergraduate science \\ classes from three disciplines at an Australian research-intensive university. A mixed- \\ methods approach was used to evaluate learning gains by collecting data from: student \\ surveys; semi-structured interviews with academic teaching staff; and student \\ performance by marking of assessment tasks. Self-reported learning gains showed $95 \%$ of \\ all students perceived improvements in their ability to do all communication skills and \\ 94\% perceived improvements in their confidence in communicating science as a result of \\ the activities. Academic teaching staff reported improvements in students' \\ communication skills and understanding of core science content, and indicated that the \\ tasks were explicit, engaging, and sustainable for use in future years. Students successfully \\ transferred their learning to their assignments, demonstrating on average, a 'good,' \\ 'excellent,' or 'outstanding' standard for each of the science communication criteria. These \\ activities provide a promising starting point for integrating employable communication \\ skills into undergraduate science degrees.
}

\section{KEYWORDS}

communication skills, undergraduate science, learning gains, higher education, science communication, teaching and learning

\section{INTRODUCTION}

The introduction of generic skills into undergraduate science degrees is becoming increasingly common and necessary in higher education. The aim of this movement is to enhance accountability in science higher education and to create a stronger link between undergraduate education and employability (Bath, Smith, Stein, \& Swann, 2004; Cummings, 1998). This is especially timely given that employers are focussing more now on the skills graduates have to offer rather than on grades achieved during their tertiary education (Yorke, 2006).

One 'generic' skillset consistently highlighted by students, graduates, employers, academics, and professionals as integral for science graduates is communication (Gray, Emerson, \& MacKay, 2005; Jones, Yates, \& Kelder,2011; Leggett, Kinnear, Boyce, \& Bennett, 2004; McInnis, Hartley, \& Anderson, 2000). Thus, communication is more frequently being included as a required learning outcome for both undergraduate and graduate science degrees across the UK, the US, Canada, and Australia (AAAS, 2009; AQF, 2013; Jones et al., 2011; OCGS, 2005; QAA, 2007). In Australia, one of five Threshold Learning Outcomes (TLOs) for the undergraduate Bachelor of Science (BSc) is 'Communication.' These TLOs are "nationally agreed upon descriptions of what a science graduate 
should know and be able to do" (ACDS, 2013). The communication TLO recommends that science graduates be able to communicate scientific results effectively "to a range of audiences, for a range of purposes, and using a variety of modes" (Jones et al., 2011).

The introduction of generic skills with this kind of broad remit presents difficulties when it comes to coherent integration and development of such skills across pre-existing science programs. Science courses (units of study) at the majority of higher education institutions (HEI) are designed as individual and discrete entities. Decisions about what content or skills to teach within each course are typically made by individual academics (also known as 'faculty') or small groups of science academics (Barrie, Hughs, Smith, \& Thomson, 2009). As a result, the communication skills commonly taught in undergraduate science courses reflect the focus of traditional research and conventional technical communication which is typical in academia (Dietz, 2013). Potential barriers facing science academics in implementing a diversity of communication tasks and skills into their teaching may include a lack of familiarity, confidence, time, resources or professional training in a breadth of communication skills. It is unreasonable to expect science academics who are under time pressures and specialists in one specific scientific subject to be masters of educating undergraduates on a topic like communication that they themselves may find challenging (Brownell, Price, \& Steinman, 2013).

Examples where diverse communication skillsets are taught in science courses are uncommon and most often the result of the novel teaching practices of an individual or a few innovative educators with a specific interest in communication. This is particularly so for general science degrees, such as the BSc. One study found that in a large sample of science assessment tasks involving communication, across five Australian universities, 96 per cent of tasks were targeted at an audience of scientists of the same discipline (Stevens, 2013). Notably, examples of assessment tasks targeting interdisciplinary science communication, or communication with lay audiences in this study were extremely rare. Examples of innovative teaching practice do exist at an individual course level both in Australia (e.g. Kuchel, Wilson, Stevens, \& Cokley, 2014; Moni, R., Hryciw, Poronnik, \& Moni, K., 2006) and in the US (e.g. Brownell, Price, \& Steinman, 2013a) but these innovations are often developed in isolation and the results rarely published in the academic literature. In order to facilitate uptake there is a need for quality, published, evidence-based resources that support academics to integrate diverse communication skills into a diversity of science courses with minimal requirements in time, extra training, funding, and resources.

In this study we designed, piloted and evaluated a set of 'template package' tutorial activities that scaffold the explicit teaching and learning of science communication with non-scientific audiences. The need to be explicit in teaching these skills is twofold. Firstly, the instructional approach of explicit teaching has been shown to be effective in teaching complex skills, such as communication, by making the purpose of learning and outcomes clear to students through scaffolded, step-by-step learning (Archer \& Hughes, 2011, p. 11; Rosenshine, 1986). Secondly, there has been evidence to support that the explicit instruction approach has had success in teaching science communication in Australia (e.g. Moni et al., 2006) and in the UK (e.g. Divan \& Mason, 2015). Finally, research shows that when communication of science with non-scientific is taught in Australian undergraduate science, it is rarely done so explicitly, or in a scaffolded manner, with the majority of communication skills being either implicit or absent from science assessment tasks (Mercer-Mapstone \& Kuchel, 2015).

Thus, these activity resources have been designed as explicit teaching and learning packages that encompass a range of adaptable 'templates' into which science academics can integrate contextand discipline-specific science content with minimal preparation. Each activity scaffolds the teaching of one or more core skills of effective science communication, and has been designed specifically to teach undergraduate science students how to communicate with non-scientific audiences (Mercer- 
Mapstone \& Kuchel, 2015). These skills aim to teach science communication at a conceptual level, rather than as a set of context-specific skills. This gives students a transferrable skillset which is applicable across a broad range of contexts, disciplines, purposes, and modes. Each activity is short and easy to implement (15 to $30 \mathrm{~min}$ ), thus facilitating integration of explicitly-taught skills into existing classes. This concept aims to overcome some of the aforementioned implementation barriers by removing the need for extra training in communication while allowing science lecturers to be confident that they are teaching relevant and well-developed communication skills, alongside science content, in a time and resource-efficient manner.

Our study addresses two research questions:

1. How can activities be designed and implemented to scaffold the effective teaching and learning of science communication in a diverse range of undergraduate science courses?

2. What learning gains are achieved by the introduction of science communication 'template package' activities in undergraduate science courses?

\section{METHODS}

Ethics approval for this study was granted by the University of Queensland Behavioural \& Social Sciences Ethical Review Committee (Approval Number: 2014000655).

\section{Teaching Implementations}

\section{Design of science communication activities}

The activities focused on the explicit teaching of seven core communication skills (Table 1) as chosen by the course coordinators to be most relevant to the corresponding assessment task. The skills were taken from an evidence-based list of core skills deemed essential for teaching undergraduate science students to communicate with non-scientific audiences (Mercer-Mapstone \& Kuchel, submitted). Not all courses taught all skills or all activities, and not all skills that were taught were assessed in the corresponding assessment tasks. Activity 'packages' with supporting resources for both instructors and students were then tailored to suit the specifications of each course, through regular consultation with the course coordinators. Each activity ran for no more than 10 to 30 minutes with the option to extend or shorten for each activity given time allowances of specific courses. Each package included the following resources:

- A multimedia PowerPoint presentation introducing the skills and the activity. The aim of the presentation was to both engage students and have them develop their own conceptions of the skills required to communicate effectively.

- Teaching notes outlining a step-by-step process for teaching and running the activity, including questions the teacher might ask students; suggestions on facilitating class discussions; worked examples; and suggested timings.

- Instructional student handouts outlining explicitly what skills would be taught; why those skills were relevant to the student; and what would be required of them in the activity.

- Activity worksheets to be filled out by students, in pairs or groups, often including a worked example.

The design of these activities was informed by best practice from the fields of higher education (e.g. Ramsden, 2003). In-class activities involved the principles of active learning which promotes "the importance of students taking an active role in the learning process" (Cook-Sather, 2011) and 'learning by doing' based on the theory that activities that are interesting and engaging to the students facilitate the retention of content (Kuh, 2008). Teaching resources were based on the theory of constructive alignment which is the process of articulating explicit learning outcomes and aligning the design of teaching activities and assessment tasks to facilitate students' ability to achieve those outcomes (Biggs \& Tang, 2011). A short description of each activity, timing, skills taught, and 
the courses into which it was implemented, is given in Appendix 1 in the Online Supplementary Material. A full example of one of the activities, including teaching notes and student handouts and worksheet, is included in Appendix 2 in the Online Supplementary Material. Teaching was delivered by the lead author.

\begin{tabular}{|c|c|}
\hline REFERENCE WORD & CORE COMMUNICATION SKILLS FOR EFFECTIVE SCIENCE COMMUNICATION \\
\hline Audience & Identify and understand a suitable target audience \\
\hline Language & Use language that is appropriate for your target audience \\
\hline Content & $\begin{array}{l}\text { Separate essential from non-essential factual content in a context that is relevant to } \\
\text { the target audience }\end{array}$ \\
\hline Context & Consider the social, political, and cultural context of the scientific information \\
\hline Style & $\begin{array}{l}\text { Use/consider style elements appropriate for the mode of communication (such as } \\
\text { humour, anecdotes, analogy, metaphors, rhetoric, images, body language, eye } \\
\text { contact, and diagrams) }\end{array}$ \\
\hline Prior knowledge & Consider the levels of prior knowledge in the target audience \\
\hline Purpose & Identify the purpose and intended outcome of the communication \\
\hline
\end{tabular}

\section{Undergraduate science courses}

The science communication activities were implemented in three undergraduate science courses ('units') at an Australian research-intensive university within the Group of Eight (Go8) coalition (eight highly-ranked research intensive universities with similar teaching cultures and missions). The implementation of these activities was used to scaffold the teaching of existing assessment tasks in two courses and modify those tasks, and to support the implementation of a newly designed assessment task in the other. The details of the courses into which activities were implemented are as follows.

- BIOL3000: a third-year biology course in 'Conservation' with 115 students. The assessment task required that students, in groups of three, produce a 3 to 5-minute radio program that discussed multiple stakeholder perspectives on a conservation issue. This course allocated a total of one and a half hours of teaching time for communication activities in a practical class setting, spread over two weeks.

- PHYS3900: a third-year physics capstone course in 'Perspectives in Physics Research' with 50 students. The assessment task required students to explain complex physics concepts to two audiences (one scientific, one non-scientific) in less than 70 words. Formative feedback was integrated by asking students to complete this task three times on different physics topics. This task was newly designed in the process of this study. This course allocated six hours of teaching time for communication activities in a tutorial class setting, spread over three weeks.

- CHEM2052: a second-year chemistry course in 'Chemical Biology' with 129 students. The assessment task required students to produce three pieces of assessment: a story pitch, a magazine article written for $\mathrm{New}$ Scientist, and a short video segment for the nightly news, all based on an academic paper from the field of chemistry. This course allocated one hour of teaching time for communication activities in a tutorial class setting, all taught in one session.

\section{Study participants}

The three courses addressed a total of 294 second- and third-year undergraduate students across the three scientific disciplines of biology, physics, and chemistry. Fifty-two percent of students were female, 82 percent were in the age bracket 19 to 23 years, $73 \%$ domestic and $27 \%$ international, 
and all were enrolled in either a single or dual Bachelor of Science or Bachelor of Biomedical Sciences degree program. The three academic course coordinators interviewed as part of data collection were all male, in either early or established academic career stages, with some being teaching-focused academics and others being research-focused.

\section{Measures of student learning}

A mixed-methods approach to triangulation across three different qualitative and quantitative data sources (Kember, 2010) was used to evaluate student learning from the implemented science communication activities. The same data were collected for all three courses, on the skills explicitly taught in each course.

\section{i. $\quad$ Student perceptions and self-reported learning gains}

Students completed a paper-based survey (Appendix 3 in Online Supplementary Material) in class upon completion of all science communication learning activities, prior to assessment. An open response question asked students to identify the most important skills they learned from the activity (based on the format of the one-minute essay; Anderson \& Burns, 2013). This was used to determine whether the intended explicit learning objectives for that activity were comprehended by students without eliciting biased answers through leading questions. Students were then asked to report (on a 5-point Likert scale: 1 = 'Not at all,' 2 = 'A little,' 3 = 'Somewhat,' 4 = 'Quite a lot,' 5 = 'Very much') their:

- level of engagement with the activity: enjoyment, perceived value to future career, relevance to assessment task;

- learning gains: the extent to which they felt their ability to do certain skills had improved; and

- self-efficacy (confidence) in communicating science to non-scientific audiences.

\section{ii. Student performance}

Marking criteria specifically designed for evaluation purposes (i.e., did not contribute to students grades on the assignment; Appendix 4 in the Online Supplementary Material) were aligned directly with the learning objectives and content of the activities. These criteria were graded on the following scale (to align with the university's grading system): 1- 3: Fail = all skills absent; 4: Poor = many faults that need extensive work; 5: Good = minor faults that need some work; 6: Excellent $=$ minor faults that are easily fixed; 7: Outstanding = no faults. To minimise marker variability, making was done by one marker upon completion of the task. Course grades for the activities were determined by the course coordinators using marking criteria that included discipline-specific content and skills as well as communication.

\section{iii. Academics' perceptions}

Academics' perceptions of student learning were recorded digitally via semi-structured interviews. Questions for the interview (Appendix 5 in the Online Supplementary Material) asked academics their perceptions of the strengths and weaknesses of the activities, potential improvements, and the sustainability of implementing the activities in subsequent years. Common themes, main points, and quotes were extracted and transcribed.

\section{DATA ANALYSIS}

Responses to the 5-point Likert scale student survey questions were treated as discrete for analysis. A conditional logit model (clm) was built to include the response variable (Likert survey answers) and the following predictor variables (and levels): discipline (biology, chemistry, or 
physics), year level (second or third), and tutorial size (small: $<50$ students, or large $>50$ students). Only the main effects were explored; interactions amongst variables were not included due to the small sample size. A likelihood ratio test was used to test for significant differences between the clm with explanatory variables and a second clm without explanatory variables (the null hypothesis). Aposteriori z-tests were used to explore differences between each combination of levels for those significant variables with more than two levels.

Open response student survey answers were analysed using thematic analysis (Braun \& Clarke, 2006). Coded categories were formulated inductively (prior to analysis) and modified deductively following a trial analysis of $30 \%$ of responses. Categories were refined until $>95 \%$ agreement was achieved in independent assessments by two researchers to guarantee their validity and repeatability in application to remaining assessments.

\section{RESULTS}

\section{Self-reported learning gains (Quantitative survey)}

Overall, 232 (79\%) of the 294 students answered the Likert scale survey questions. Table 2 gives descriptive statistics (mean and standard deviation) of quantitative survey responses for selfreported learning gains. On average, across all communication skills, $94.9 \pm 0.2 \%$ of students reported improvements in their ability to carry out all communication skills taught across all subjects. Student perceptions of improvement in their ability to "consider the social, political, or cultural context of a scientific issue" and to "visualize data effectively" differed significantly between courses. Students in third-year biology $(n=86)$ reported significantly more improvement in the skill involving context than second-year chemistry students $\left(n=109\right.$, LRT $\left.^{2}{ }_{1}=5.529, \mathrm{p}=0.018\right)$. Secondyear chemistry students reported significantly more improvement in their ability to visualise data than third-year physics students $\left(\mathrm{n}=37, \mathrm{LRT}^{2}{ }_{1}=18.458, \mathrm{p}=0.003\right)$.

\section{Student engagement and self-efficacy (Quantitative survey)}

Of the 232 students who answered the Likert-scale survey questions, the majority (94.4\%) reported improvements in their confidence in communicating science to non-scientific audiences as a result of the activities. Table 2 gives descriptive statistics of quantitative survey responses for student engagement and self-efficacy. Students' enjoyment of the communication activities varied significantly among subjects ( $\operatorname{LRT} \chi_{2}^{2}=12.755, \mathrm{p}=0.002$ ). Both second-year chemistry and third-year physics students enjoyed the activities more than third-year biology students $(\mathrm{z}=3.462, \mathrm{p}<0.001$; $\mathrm{z}=2.073, \mathrm{p}=0.038$, respectively). Enjoyment was also significantly different between year levels and between tutorial sizes, with the second-year students (chemistry) enjoying the activities more than third-year students (biology and physics; $\left.\operatorname{LRT} \chi_{1}{ }_{1}=8.438, \mathrm{p}=0.004\right)$. Students in small tutorial sizes enjoyed activities more than those in large tutorial sizes ( $\operatorname{LRT} \chi_{1}^{2}=10.903, \mathrm{p}<0.001$ ). Students (on average) from each course placed different value on communication skills for their intended career, with biology students rating them as very valuable (Mode $=5 / 5)$, chemistry students as quite valuable $($ Mode $=4 / 5)$, and physics students as only somewhat valuable (Mode $=3 / 5)$. Students across all courses rated the communication skills as relevant to their assignments with very little variation. It should be noted that each of the above comparisons was partly confounded as a consequence of the small number of courses involved.

\section{Visibility of learning objectives to students (Qualitative survey-thematic analysis)}

A response rate of $64 \%(n=188$ students) was obtained for the open response, one-minute essay question: 'Please take a minute to write down what you felt were the main skills you learnt in the communication activities.'The most common theme in responses across all three subjects 
Table 2. Descriptive statistics (Mean = $M$, and Standard Deviation = SD) of student Likert-scale responses to questions asking about engagement, self-efficacy, and self-reported learning gains, split by discipline, year level, and tutorial size. Answers were given on a 5-point Likert-scale from ' 1 = not at all' to $5=$ 'very much.' NA indicates that skill was not taught in that discipline, year level, or tutorial size.

\begin{tabular}{|c|c|c|c|c|c|c|c|c|c|c|c|c|c|c|c|}
\hline & & \multicolumn{6}{|c|}{ DISCIPLINE } & \multicolumn{4}{|c|}{ YEAR LEVEL } & \multicolumn{4}{|c|}{ TUTORIAL SIZE } \\
\hline & & \multicolumn{2}{|c|}{ BIOLOGY } & \multicolumn{2}{|c|}{ CHEMISTRY } & \multicolumn{2}{|c|}{ PHYSICS } & \multicolumn{2}{|l|}{ THIRD } & \multicolumn{2}{|c|}{ SECOND } & \multicolumn{2}{|l|}{ LARGE } & \multicolumn{2}{|c|}{ SMALL } \\
\hline & & $M$ & SD & $M$ & SD & $M$ & SD & $M$ & SD & $M$ & SD & $M$ & SD & $M$ & SD \\
\hline \multirow{4}{*}{$\begin{array}{l}\text { Engagement } \\
\text { and self- } \\
\text { efficacy }\end{array}$} & Confidence & 3.31 & 0.92 & 3.16 & 0.91 & 3.03 & 1.12 & 3.23 & 0.99 & 3.16 & 0.91 & 3.23 & 0.95 & 3.09 & 0.97 \\
\hline & Enjoyment & 2.87 & 0.90 & 3.32 & 0.94 & 3.22 & 0.89 & 2.98 & 0.91 & 3.32 & 0.94 & 3.02 & 0.91 & 3.45 & 0.94 \\
\hline & Relevance & 3.90 & 0.88 & 3.89 & 0.85 & 3.89 & 0.91 & 3.89 & 0.89 & 3.89 & 0.85 & 3.83 & 0.87 & 4.06 & 0.85 \\
\hline & Future Value & 4.06 & 0.94 & 4.06 & 0.78 & 3.70 & 1.02 & 3.95 & 0.97 & 4.06 & 0.78 & 4.03 & 0.85 & 3.91 & 0.97 \\
\hline \multirow{8}{*}{$\begin{array}{l}\text { Self-reported } \\
\text { learning gains } \\
\text { for each skill }\end{array}$} & Audience & 3.47 & 0.88 & 3.27 & 0.96 & 3.08 & 1.12 & 3.35 & 0.97 & 3.27 & 0.96 & 3.36 & 0.92 & 3.17 & 1.06 \\
\hline & Language & 3.37 & 0.85 & 3.26 & 0.99 & 3.03 & 1.17 & 3.27 & 0.97 & 3.26 & 0.99 & 3.31 & 0.93 & 3.14 & 1.08 \\
\hline & $\begin{array}{l}\text { Prior } \\
\text { Knowledge }\end{array}$ & 3.37 & 0.90 & 3.24 & 1.03 & 3.16 & 1.14 & 3.31 & 0.98 & 3.24 & 1.03 & 3.29 & 0.99 & 3.23 & 1.02 \\
\hline & Context & 3.35 & 0.93 & 3.02 & 1.05 & NA & NA & 3.35 & 0.93 & 3.02 & 1.05 & 3.14 & 1.05 & 3.30 & 0.78 \\
\hline & Content & 3.34 & 0.86 & 3.34 & 1.04 & 3.27 & 1.15 & 3.32 & 0.95 & 3.34 & 1.04 & 3.28 & 0.98 & 3.45 & 1.01 \\
\hline & Style & NA & NA & NA & NA & 3.03 & 1.04 & 3.03 & 1.04 & NA & NA & NA & NA & 3.03 & 1.04 \\
\hline & $\begin{array}{l}\text { Data } \\
\text { Visualisation }\end{array}$ & NA & NA & 3.45 & 1.07 & 2.73 & 1.41 & 2.73 & 1.41 & 3.45 & 1.07 & 3.41 & 1.05 & 3.08 & 1.35 \\
\hline & & 3.52 & 0.85 & NA & NA & NA & NA & 3.52 & 0.85 & NA & NA & 3.52 & 0.85 & NA & NA \\
\hline
\end{tabular}

related to 'Target Audience' (68.1\%) followed by the ability to 'Translate complex science language into simple language for different audiences' (40.9\%). The most common sub-theme relevant to 'target audience' identified in these responses was the ability to "Recognise/identify the existence and/or the importance of different/suitable target audiences" (28.8\%). Chemistry $(\mathrm{n}=95)$ and physics $(\mathrm{n}=35)$ students highlighted the 'style' elements of data visualisation and infographics in $37.9 \%$ and $20.0 \%$ of their responses respectively. The use of appropriate style elements was a predominant theme for physics students, with the ability to use analogy, metaphor, and simile being cited in $48.6 \%, 20.0 \%$, and $20.0 \%$ of answers respectively. Skills involving the ability to 'Consider the levels of prior knowledge in the target audience' and 'Separate essential from non-essential factual content' were present in a much higher proportion of the responses from physics students ( $26.0 \%$ and $20.0 \%$ for each skill respectively) than from biology ( $3.4 \%$ and $0 \%$ for each skill respectively, $n=58)$ or chemistry students ( $8.4 \%$ and $3.2 \%$ for each skill respectively). Thus, the predominant skills highlighted through these open 
response themes aligned with the stated learning outcomes for the respective activities, indicating that the skills were made explicit and visible to students. Other skills that students said they had gained from the activities included the simplification and understanding of scientific concepts, clarity and conciseness, problem solving and creativity, group work, the ability to make communication interesting or engaging, and the need to communicate without bias.

\section{Quantitative student performance}

Overall, $97.5 \%$ of all assessment tasks across all three courses were completedto a 'good,' 'excellent,' or 'outstanding' standard when science communication criteria were averaged for each task. The grades reported in the following section are on a scale of one (fail) to seven (outstanding) and descriptive statistics for individual criteria across disciplines are given in Table 3.

BIOL3000 assignments ( $\mathrm{n}=16$ assessment tasks produced by groups of three students for each assignment) were assessed across eight of the relevant communication criteria (Appendix 4). The average grade for all communication criteria across all assignments was $5.88 \pm 0.11$ or 'Good with minor faults that need some work.' Groups scored highest for the criterion 'Separating essential from non-essential scientific content' ( $\bar{x}=6.31$ or 'Excellent') and least well on 'Identifying a suitable audience' $(\bar{x}=4.06$ or 'Poor'). Grades were fairly uniform across the other seven criteria with averages ranging from $6-6.31$.

PHYS3900 assignments $(\mathrm{n}=29)$ were marked across four of the relevant communication criteria. The average grade for all communication criteria across all assignments was $5.89 \pm 0.09$ or 'Good with minor faults that need some work.' Students scored highest for the criterion ' $U$ sing language appropriate for the target audience' ( $\bar{x}=6.25$ or 'Excellent') and least well on 'Separating essential from non-essential scientific content' ( $\bar{x}=5.60$ or 'Good').

CHEM2052 assignments $(n=37)$ were marked across four of the relevant communication criteria. The average grade for all communication criteria across all assignments was $5.53 \pm 0.52$ or 'Good with minor faults that need some work.' Students scored highest for the criterion 'separating essential from non-essential scientific content' ( $\bar{x}=5.86$ or 'Good) and least well on 'Use appropriate stylistic elements relevant to the audience' ( $\bar{x}=4.76$ or 'Poor').

Table 3. Descriptive statistics (Mean $=M$, and Standard Deviation $=S D$ ) of assessment task grades (on a scale of $1=$ fail, to $7=$ outstanding) for each science communication marking criteria, split by disciplines. NA indicates that criteria were not assessed in those disciplines.

\begin{tabular}{l|ll|ll|ll}
\hline \multirow{2}{*}{ CRITERIA } & \multicolumn{2}{|l|}{ BIOLOGY } & \multicolumn{2}{l|}{ CHEMISTRY } & \multicolumn{2}{l}{ PHYSICS } \\
\cline { 2 - 7 } & $\mathrm{M}$ & SD & M & SD & M & SD \\
\hline Audience & 4.06 & 2.11 & NA & NA & NA & NA \\
Language & 6.06 & 0.85 & 5.78 & 1.13 & 6.25 & 0.84 \\
Purpose & 6.06 & 0.89 & NA & NA & NA & NA \\
Prior Knowledge & 6.13 & 0.81 & 5.70 & 1.10 & 5.99 & 0.94 \\
Context & 6.19 & 0.89 & NA & NA & NA & NA \\
Style & NA & NA & 4.76 & 1.48 & 5.63 & 1.04 \\
Content & 6.31 & 0.60 & 5.86 & 0.86 & 5.60 & 1.00 \\
\hline
\end{tabular}

\section{Academic perceptions (qualitative interviews)}

The three academic course coordinators overseeing the courses in this study individually agreed that the teaching of science communication skills in the activities was clear and explicit. The course coordinator from second-year chemistry noted that the approach of introducing students to the communication skills and engaging them in "developing their own conceptions" through class 
discussions was engaging and that the students would "probably have longer term memories of those [communication] strategies than if it was a straight 'infodump'." All academics agreed that the skills taught would be highly relevant and useful in helping students to complete the assessment tasks to a high standard. The course coordinator from third-year physics stated that he "saw it as a big improvement on what we were doing last year. The things that made it better were that we were teaching, practicing, and testing some specific [communication] skills" as opposed to a more tacit concept of communication. All academics thought that students received the activities positively and the course coordinator from third-year physics noted that "most students were very enthusiastic ... the number [of unenthusiastic students] was much less than in previous years.”

\section{Communication facilitating science content}

The course coordinator from third-year physics highlighted that in teaching communication he also taught science:

I was very pleased with the idea of using specific concepts from physics meaning that I could work in two objectives from the course: one was to teach communication skills but the other one was to teach core physics content.

The course coordinator from second-year chemistry also agreed that the teaching of communication skills aided the teaching of science skills by highlighting areas in need of improvement for student understanding of science.

\section{Improvements pre-and post-implementation}

Academics were asked their perceptions on whether they thought there were differences between 2013 communication assessment tasks (pre-implementation) compared to the 2014 tasks (post-implementation). All three academics stated that there had been a definite increase in the standard of student work. The course coordinator from third-year physics believed the tutorials led to more clarity of expectations: "I think the students... had more direction and more understanding of what the aim [of the assessment task] was." The course coordinator from second-year chemistry answered:

There was a difference [in quality] and in the right direction... Students were more focused on tailoring the message to the audience. There was a decrease in the use of scientific jargon without explanation. There was an increase in the use of analogy... The structure of the videos was better, with better linking of segments.

The course coordinator from third-year biology perceived a change in students' attitudes towards the assessment task, stating that students "certainly took it more seriously this year."

\section{Sustainability of activities}

All academics stated that they intended to implement the same learning activities and materials again in future years. The course coordinator from third-year biology, who had expressed hesitance about teaching communication skills initially, stated that "having been involved this year I'd be very comfortable re-teaching it." The course coordinator from second-year chemistry highlighted that "the most useful aspect [of the activities] is actually having something compiled and ready to go that you can tweak around the edges." Areas for improvement included the need for smaller tutorial sizes in BIOL3000 and CHEM2052, and either more time or better strategies for managing the larger tutorial sizes. 


\section{DISCUSSION}

This study found that explicit teaching of science communication skills leads to: improvements in science students' and instructors' perceptions of students' abilities to apply those skills; engagement with communication skills; and, overall confidence in communicating science. This conclusion is supported by the alignment of results from the multiple qualitative and quantitative data sources. Our findings provide support for the efficacy of using an instructional design approach, such as explicit instruction or direct explanation, to teaching communication in science degrees.

Results suggest that the trialled science communication activities are transferrable across science disciplines and year levels whilst maintaining high standards of perceived learning gains. This is evidenced by the finding that there were no significant differences in learning gains for six of the eight skills taught across courses, indicating that teaching and learning generally were uniform for those skills. This outcome supports the development of these activities into 'templates' that can be adapted by academics to suit a wide range of science contexts. It is likely that having the same person deliver the teaching of these activities in all courses in this study contributed to the uniformity in learning gains. Further research is required to determine whether outcomes and standards are maintained in different university settings and when delivered by different instructors.

There were two exceptions to this consistency in learning gains: the significant differences in learning gains between courses that taught context and data visualization (see Table 1 for skill details). These differences could be explained by variances in student cohorts or differences in teaching delivery or time allocated in each course, but initial findings suggest they may have been due to the relevance of those skills to the corresponding assessment tasks. Not all skills that were taught in each course were assessed in the corresponding assessment tasks. Data trends from thematic analysis of open responses on student surveys and students' self-reported learning gains indicate that students found skills that were going to be assessed to be more explicit and visible than those that were not assessed. This suggests that students focussed selectively on assessable skills and hence the teaching of those skills had a higher impact. This was shown in both instances with significant differences in learning gains: chemistry students reported significantly higher learning gains than physics in their ability to visualize data and data visualization was assessed in the chemistry but not the physics course. Likewise, biology students reported significantly higher learning gains than chemistry students in their ability to consider the social, political, or cultural context of a scientific issue, which was assessed in the biology assessment task but not for that task in chemistry. These results support the large body of evidence that suggests assessment is central to the quality of learning outcomes in higher education and is critical to optimal student learning and retention (Biggs \& Tang, 2011; Crooks, 1998; Harden \& Crosby, 2000; Morgan Clarke, Weidmann, Laidlaw, \& Law, 2007). It also indicates that academics should assess the science communication skills taught for optimal outcomes in future implementations. The teaching and learning resources supplied online with this article provide useful examples that may be adopted or modified by interested teaching academics.

Teaching innovations in higher education are notoriously short-lived, dependent on the motivations of individual academics or on transitory support and resources. Hence it is imperative for innovations that target skills and knowledge of high value or impact to have sustainability at the core of their design. Sustainability is facilitated by at least two factors: the recognition by academic staff of value or importance to student learning and the relative ease of implementation and management. Feedback from academics involved in the study indicate that the design of the activities is likely to be sustainable given that all academics said that they would continue to teach the activities and tasks in the same courses in future years. The structuring of the resources as templates contributed to this sustainability, with one academic stating that "the most useful aspect [of the 
activities] is actually having something compiled and ready to go that you can tweak around the edges" making it quick and easy to implement. Sustainability is imperative to the efficacy of these activities as 'template packages.' Broader adoption and further testing is required in different contexts such as disciplines, year levels, and universities to confirm their transferability, effect on learning outcomes and sustainability. Given similarities in student cohorts, assessment, and teaching practices at research intensive universities, particularly the Go8 in Australia (Australian Government Department of Industry, 2013; Universities Australia, 2014; Stevens, 2013), as well as the breadth and depth of BSc programs between institutions (Varsavsky, Matthews \& Hodgson,2013), prospects are promising. Such further research will also be useful in separating the effects of year level, subject, and tutorial size without the partial confounding of those factors which was a limitation of this study as a result of the small sample size.

Students generally performed very well against the science communication marking criteria in this study. The exception was that biology students generally completed the identification of a target audience poorly. This could be because students did not receive marking criteria until after completing the task as summative feedback (physics and chemistry received them at the start of the task), or because the assessment outline did not state the expectations sufficiently clearly. Education research shows that providing criteria prior to assessment clarifies students' expectations and helps to standardise the quality of student work and consistency in marking (Brown, Race, \& Rust, 1995; McDonald \& Sansom, 1979; Saunders \& Davis, 2014).

This study also found evidence that aligned with a growing body of research suggesting that teaching communication with non-scientific audiences in science courses facilitates the learning of technical science rather than distracting from it. Both student and academic feedback noted the learning of subject-specific science content through the communication activities. This finding aligns with a similar study at Stanford University (Brownell et al., 2013) that found the teaching of communication to non-scientific audiences in a neuroscience course significantly improved understanding of original scientific literature, aided students' critical analyses, and improved communication skills. Other studies also provide evidence that communication assessment tasks in science degrees lead to learning gains in skills such as quantitative reasoning, interpretation of scientific results, and learning of core science content at a conceptual level (e.g., Kuchel, et al., 2014; Greenbowe \& Shroeder, 2008; Moni et al., 2007; Stevens, 2013). As such, tasks that require students to communicate with non-scientists may provide a successful approach to integrating more generic communication skills into science degrees.

The need for smaller tutorial sizes was highlighted by both students and academics in chemistry and physics. Communication lends itself to a discursive and developmental teaching format which is harder to deliver in-depth in large classes. This was indicated by the fact that smaller classes in physics and chemistry enjoyed the activities significantly more than large classes in chemistry and biology, although this factor was confounded partially with subject and should be used as an indication for further research only. It is the recommendation of this study that class sizes of 30 students or fewer would be ideal for these activities. This restriction on class size is supported by Bandiera, Larcinese, and Rasul (2010) who found that tertiary student achievement decreased as class size increased in the UK, indicating that smaller classes optimize student learning. That said, learning gains were still high in large classes indicating that large student numbers did not detrimentally affect student learning, only enjoyment. It would be worthwhile investigating whether the standard of learning would improve further should these changes be made in future years.

In facilitating the dissemination and uptake of these 'template package' activities, we can look to previous examples of successful pedagogical practice. For example, Divan and Mason (2015) took a programme-wide approach to developing science-specific communication skills in a biosciences graduate program in the UK. One part of this process took the approach of 'writing 
across the curriculum' (Craig, 2011) which involved integrating communication activities into specialist courses across the degree program with positive results. Some of the foremost strengths of this approach highlighted by academic staff in the program were: making expectations explicit; having multiple iterations for practice; embedding skills within the curriculum; and being able to "customise generic training materials to make them discipline-specific" (Divan \& Mason, 2015, p. 16). Those results align closely with the results from the similar approach taken by our study and provide support for the growing body of evidence showing the efficacy of teaching communication in a discipline-specific context across a science curriculum. The design of the template package activities directly facilitates this pedagogical approach, and with further research, could be an effective way of developing communication skills in science degrees.

\section{CONCLUSION AND FUTURE RESEARCH}

The science communication 'template package' activities designed, piloted, and evaluated in this study saw increases in students' perceived abilities and confidence to carry out a wide range of science communication skills. Students were able to transfer and apply those skills successfully within the context of assessment tasks. Academics saw the activities as explicit, engaging, and sustainable. The provision of tested and validated science communication template package activities that can be adapted to specific science courses across year levels, disciplines, and potentially, HEI, is a promising approach to overcoming the commonly cited implementation barriers of time-poor academic staff, as well as a lack of resources and skill-specific knowledge. Such template packages also ensure that the communication skills being taught are explicit and relevant to students, and successful in achieving the intended learning outcomes when combined with constructively aligned assessment tasks and marking rubrics, such as the adaptable rubric used in this study. The learning activities designed for this project represent a starting point for this endeavour.

Future research should focus on expanding the sample size, which was a limitation of this study, to remove confounding factors by implementing the activities in a wider range and number of disciplines, courses, year levels, class sizes, and universities. This would yield further data as to the transferability and sustainability of the activities.

Should teaching academics wish to implement the activities trialled in this study, please do not hesitate to contact the corresponding author. We are happy to provide the template activity packages, along with marking criteria, all of which can be adapted to the specificities of an individual course context. We are also happy to provide the evaluative tools used in this study to aid in the process of evidencing learning. We ask only that, where possible, we be kept abreast of the progress and evaluation of such implementations in an effort to inform future research.

\section{ACKNOWLEDGEMENTS}

Thanks go to the three course coordinators, Dr. John Dwyer, Prof Michael Drinkwater, and Dr. Philip Sharpe, for facilitating the development and implementation of the activities and for allowing access to their courses. Their advice and participation were invaluable. Thanks also to the tutors who worked hard to aid in the delivery of teaching in class. As always, gratitude to Bruce and Gina for their tireless and intuitive feedback.

Lucy Mercer-Mapstone is a PhD candidate at the Sustainable Minerals Institute and a co-fellow at the Institute for Teaching and Learning Innovation at the University of Queensland.

Louise Kuchel is a Teaching Focussed Lecturer at the School of Biological Sciences, Faculty of Science, at the University of Queensland. 


\section{REFERENCES}

Academic Council of Deans of Science (ACDS). (2013). Background: Science threshold learning outcomes.

American Association for the Advancement of Science (AAAS). (2009). Cultivating biological literacy. In: Vision and change in undergraduate biology: A call to action.

Anderson, D., \& Burns, S. (2013). One-minute paper: Student perception of learning gains. College Student Journal, 47(1), 219-227.

Archer, A., \& Hughes, C. (2011). Explicit instruction: Effective and efficient teaching. New York: Guilford Press.

Australian Government Department of Industry (2013). Higher Education Statistics.

Australian Qualifications Framework (AQF, 2013). AQF Specification for the Masters Degree.

Bandiera, O., Larcinese, V., \& Rasul, I. (2010). Heterogeneous class size effects: New evidence from a panel of university students*. The Economic Journal, 120(549), 1365-1398. doi: 10.1111/j.14680297.2010.02364.x

Barrie, S., Hughes, C., Smith, C., \& Thomson, K. (2009). Key issues to consider in the renewal of learning and teaching experiences to foster graduate attributes.

Bath, D., Smith , C., Stein, S., \& Swann, R. (2004). Beyond mapping and embedding graduate attributes: Bringing together quality assurance and action learning to create a validated and living curriculum. Higher Education Research \& Development, 23(3), 313-328. doi: 10.1080/0729436042000235427

Biggs, J. B., \& Tang, C. (2011). Teaching For quality learning at university. Maidenhead, UK: McGraw-Hill Education.

Braun, V., \& Clarke, V. (2006). Using thematic analysis in psychology. Qualitative Research in Psychology, 3(2), 77-101. doi: http://dx.doi.org/10.1191/1478088706qp063oa

Brown, S., Race, P., \& Rust, C. (1995). Using and experiencing assessment. Assessment for learning in higher education. London: Kogan-Page.

Brownell, S. E., Price, J. V., \& Steinman, L. (2013). Science communication to the general public: Why we need to teach undergraduate and graduate students this skill as part of their formal scientific training. Journal of Undergraduate Neuroscience Education, 12(1), E6-E10.

Brownell, S. E., Price, J. V., \& Steinman, L. (2013a). A writing-intensive course improves biology undergraduates' perception and confidence of their abilities to read scientific literature and communicate science. Advances in Physiology Education, 37(1), 70-79. doi: 10.1152/advan.00138.2012

Cook-Sather, A. (2011). Lessons in higher education: Five pedagogical practices that promote active learning for faculty and students. Journal of Faculty Development, 25 (3), 33-39.

Craig, L. (2011). Writing across the curriculum: A brief summary of pedagogy and practices . Cambridge: Massachusetts Institute of Technology.

Crooks T. (1998). The impact of classroom evaluation practices on students. Assessment in Education, 5,131 7.

Cummings, R. (1998). How should we assess and report student generic attributes?

Dietz, T. (2013). Bridging values and deliberation to science communication. PNAS, 110, 14081-14087. doi: $10.1073 /$ pnas. 1213532110

Divan, A., \& Mason, S. (2015). A programme-wide training framework to facilitate scientific communication skills development amongst biological sciences masters students. Journal of Further and Higher Education, 1-25. doi: 10.1080/0309877X.2014.1000276

Gray, F. E., Emerson, L., \& MacKay, B. (2005). Meeting the demands of the workplace: Science students and written skills. Journal of Science Education and Technology, 14(4), 425-435. doi: 10.1007/s10956005-8087-y

Greenbowe, T. J., \& Schroeder, J. D. (2008). Implementing POGIL and the science writing heuristic jointly in undergraduate organic chemistry-Student perceptions and performance. Chemistry Education Research and Practice, 9,149-156.

Harden, R. M., \& Crosby, J. R. (2000). AMEE education guide no. 20: The good teacher is more than a lecturer-The twelve roles of the teacher. Medical Teaching, 22, 334-47.

Jones, S., Yates, B., \& Kelder, J. A. (2011). Learning and teaching academic standards project: Science learning and teaching academic standards statement.

Kember, D. (2003). To control or not to control: The question of whether experimental designs are appropriate for evaluating teaching innovations in higher education. Assessment and Evaluation in Higher Education, 28(1), 89-101. 
Kuchel, L., Wilson, R., Stevens, S., \& Cokley J. (2014). A documentary video assignment to enhance learning in large first-year science classes. International Journal of Innovation in Science and Mathematics Education, 22(4), 48-64.

Kuh, G. D. (2008). Why integration and engagement are essential to effective educational practice in the twenty-first century. Peer Review, 10, 27-28.

Leggett, M., Kinnear, A., Boyce, M., \& Bennett, I. (2004). Student and staff perceptions of the importance of generic skills in science. Higher Education Research \& Development, 23(3), 295-312. doi: 10.1080/0729436042000235418

McDonald, R., \& Sansom, D. (1979). Uses of assignment attachments in assessment. Assessment in Higher Education, 5, 45-55.

McInnis, C., Hartley, R., \& Anderson, M. (2000). What did you do with your science degree? A national study of employment outcomes for science degree holders 1990-2000.

Mercer-Mapstone, L. D., \& Kuchel, L. J. (2015). Core skills for effective science communication: A teaching resource for undergraduate science education. International Journal of Science Education, Part B: Communication and Public Engagement. doi: 10.1080/21548455.2015.1113573

Mercer-Mapstone, L. D., \& Kuchel, L. J. (2015). Teaching scientists to communicate: Evidence-based assessment for undergraduate science education. International Journal of Science Education. 37(10), 1613-1638. doi:10.1080/09500693.2015.1045959

Moni, R. W., Hryciw, D. H., Poronnik, P., \& Moni, K. B. (2007). Using explicit teaching to improve how bioscience students write to the lay public. Advances in Physiology Education, 31, 167-75. doi: 10.1152/advan.00111.2006

Morgan, M. K., Clarke, R., Weidmann, M., Laidlaw, J., \& Law, A. (2007). How assessment drives learning in neurosurgical higher training. Journal of Clinical Neuroscience 14(4), 349-354. doi: http://dx.doi.org/10.1016/j.jocn.2005.12.011

Ontario Council of Graduate Studies (OCGS, 2005). Graduate Degree Level Expectations.

Quality Assurance Agency UK (QAA, 2007). Subject Benchmark Statement: Biosciences.

Ramsden, P. (1992). Learning to teach in higher education. London: Routledge.

Rosenshine, B. (1986). Synthesis of research on explicit teaching. Educational Leadership, 43(7), 60-69.

Saunders, M. N. K., \& Davis, S. M. (1998). The use of assessment criteria to ensure consistency of marking: Some implications for good practice. Quality Assurance in Education, 6(3), 162-171. doi: doi:10.1108/09684889810220465

Shute, V. J. (2008). Focus on formative feedback. Review of Educational Research, 78(1), 153-189. doi: $10.2307 / 40071124$

Stevens, S. (2013). What communication skills are taught in Australian science degrees and what else do students learn from "communication to non-scientists" tasks? (Unpublished honours thesis). University of Queensland, Brisbane, Australia.

Universities Australia (2014). Student numbers and characteristics.

Varsavsky, C., Matthews, K. E., \& Hodgson, Y. (2013). Perceptions of science graduating students on their learning gains. International Journal of Science Education, 36(6), 929-951. doi: 10.1080/09500693.2013.830795

Yorke, M. (2006). Employability in higher education: What it is—What it is not. York: Higher Education Academy.

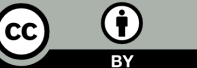

Copyright for the content of articles published in Teaching \& Learning Inquiry resides with the authors, and copyright for the publication layout resides with the journal. These copyright holders have agreed that this article should be available on open access under a Creative Commons Attribution License 4.0 International (https://creativecommons.org/licenses/by/4.0). The only constraint on reproduction and distribution, and the only role for copyright in this domain, should be to give authors control over the integrity of their work and the right to be properly acknowledged and cited, and to cite Teaching \& Learning Inquiry as the original place of publication. Readers are free to share these materials - as long as appropriate credit is given, a link to the license is provided, and any changes are indicated. 